S. Uslar

Klinik für Neurologie und klinische Neurophysiologie, Philippusstift, Essen, Deutschland

\title{
Gangataxie und psychotische Symptomatik bei 76-jähriger Patientin
}

\author{
Machen Sie mit beim Neuro-Quiz!
}
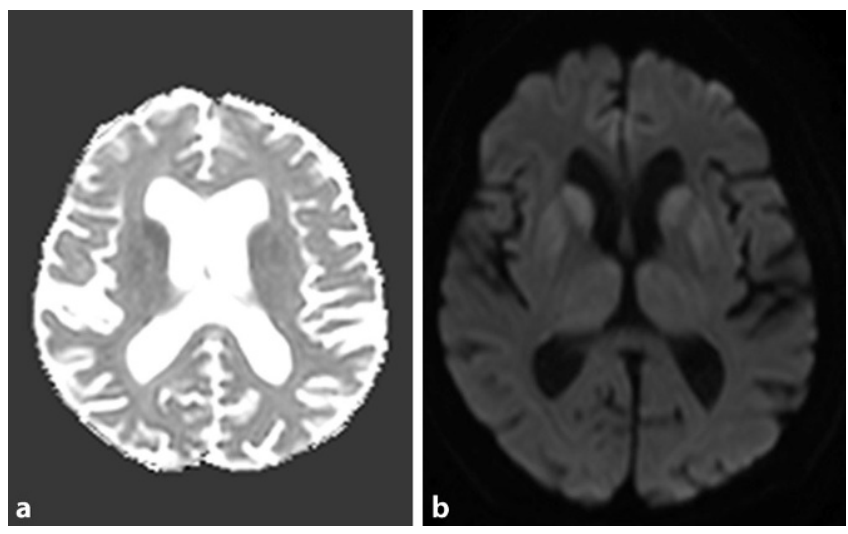

Abb. 1 Kraniale Magnetresonanztomographie, a dADC (scheinbare Diffusionskonstante [ADC: „apparent diffusion coefficient“]), b DWl (Diffusionswichtung [„,diffusion weighted imaging "])

Eine 76-jährige Frau wurde mit einer rasch progredienten Gangataxie mit rezidivierenden Stürzen in der neurologischen Notfallambulanz vorgestellt. Die Beschwerden hätten vor etwa 2 Monaten mit einer leichten Gangunsicherheit begonnen. Zuvor sei die Patientin völlig gesund und selbstversorgend gewesen. Inzwischen sei sie auf den Rollator angewiesen. Kurz vor Beginn der Symptome habe es ein traumatisches Lebensereignis gegeben, weswegen die Angehörigen hier einen Zusammenhang vermuteten.

Im psychopathologischen Befund fiel eine depressiv-ängstlich Stimmungslage auf. Eine initiale MRT (Magnetresonanztomographie) des Schädels erbrachte bis auf eine mäßig ausgeprägte zerebrale Mikroangiopathie einen Normalbefund. Der liquordiagnostische Befund war unauffällig (keine Pleozytose oder Proteinerhöhung), die Untersuchungsergebnisse auf antineuronale Antikörper waren negativ. Die EEG (Elektroenzephalographie) sowie die elektrophysiologischen Untersuchungen inklusive Elektroneurographie, Elektromyographie sowie motorisch und sensibel evozierter Potenziale erbrachten Normalbefunde.

Eine probatorisch durchgeführte Kortisonstoßtherapie führte $\mathrm{zu}$ keiner Besserung der Symptomatik. Bei weiterhin rasch progredienter Ataxie sowie inzwischen hinzugetretenen psychotischen Symptomen mit optischen Halluzinationen und Wahngedanken erfolgte nach Ablauf von 4 Wochen eine erneute MRT des Schädels, die den in Abb. 1 dargestellten Befund erbrachte.

\section{Wie lautet Ihre Diagnose?}

\section{Die Auflösung des Neuro-Quiz finden Sie in der nächsten Ausgabe von DGNeurologie}

Sie können nicht warten? Sie finden die Auflösung des NeuroQuiz „Gangataxie und psychotische Symptomatik bei 76-jähriger Patientin“ schon heute auf der Homepage der Deutschen Gesellschaft für Neurologie unter www.dgn.org/neuroquiz sowie auf SpringerMedizin.de unter www.springermedizin.de/ dgneurologie.

\section{Korrespondenzadresse}

\section{S. Uslar}

Klinik für Neurologie und klinische Neurophysiologie,

Philippusstift

Hülsmannstraße 17, 45355 Essen, Deutschland

S.Uslar@kk-essen.de

\section{Einhaltung ethischer Richtlinien}

Interessenkonflikt. S. Uslar gibt an, dass kein Interessenkonflikt besteht.

Für diesen Beitrag wurden von der Autorin keine Studien an Menschen oder Tieren durchgeführt. Für die aufgeführten Studien gelten die jeweils dort angegebenen ethischen Richtlinien.

\section{Redaktion}

J. Becker, Essen

F.A. Hoffmann, Halle (Saale)

DGNeurologie 2020 3 (3): 272

https://doi.org/10.1007/s42451-020-00175-9

Online publiziert: 8. April 2020

(c) Springer Medizin Verlag GmbH, ein Teil von Springer Nature 2020 